\title{
Boosting Photoelectrochemical Water Oxidation of Hematite in Acidic Electrolytes by Surface State Modification
}

\author{
Peng-Yi Tang, Li-Juan Han, Franziska Simone Hegner, Paul Paciok, Martí Biset-Peiró, \\ Hong-Chu Du, Xian-Kui Wei, Lei Jin, Hai-Bing Xie, Qin Shi, Teresa Andreu, \\ Mónica Lira-Cantú, Marc Heggen, Rafal E. Dunin-Borkowski, Núria López, \\ José Ramón Galán-Mascarós, Joan Ramon Morante,* and Jordi Arbiol*
}

State-of-the-art water-oxidation catalysts (WOCs) in acidic electrolytes usually contain expensive noble metals such as ruthenium and iridium. However, they too expensive to be implemented broadly in semiconductor photoanodes for photoelectrochemical (PEC) water splitting devices. Here, an Earth-abundant CoFe Prussian blue analogue (CoFe-PBA) is incorporated with core-shell $\mathrm{Fe}_{2} \mathrm{O}_{3} / \mathrm{Fe}_{2} \mathrm{TiO}_{5}$ type II heterojunction nanowires as composite photoanodes for PEC water splitting. Those deliver a high photocurrent of $1.25 \mathrm{~mA} \mathrm{~cm}^{-2}$ at $1.23 \mathrm{~V}$ versus reversible reference electrode in acidic electrolytes $(\mathrm{pH}=1)$. The enhancement arises from the synergic behavior between the successive decoration of the hematite surface with nanolayers of $\mathrm{Fe}_{2} \mathrm{TiO}_{5}$ and then, CoFe-PBA. The underlying physical mechanism of performance enhancement through formation of the $\mathrm{Fe}_{2} \mathrm{O}_{3} / \mathrm{Fe}_{2} \mathrm{TiO}_{5} /$ CoFe-PBA heterostructure reveals that the surface states' electronic levels of hematite are modified such that an interfacial charge transfer becomes kinetically favorable. These findings open new pathways for the future design of cheap and efficient hematite-based photoanodes in acidic electrolytes.
For the design of a beneficial device structure, in which both electrodes are exposed to the same medium, and considering that the hydrogen evolution is most efficiently carried out in acidic electrolyte and the advantages of the proton exchange membrane, a robust photoanode would be highly desirable. ${ }^{[10-15]}$ Nonetheless the development of an efficient and affordable photoanode, which is stable in acidic electrolyte, imposes a great challenge and limits the large-scale implementation of economically viable PEC water-splitting. In light of this challenge, much attention has been drawn to the development of efficient and affordable photoanode systems adapted to acidic electrolytes.

Hematite is arguably the most desirable photoanode material. On one hand, its relatively small bandgap of 1.9-2.1 eV and its suitably aligned valence band level perfectly match the thermodynamic energy requirements needed to drive water oxidation. ${ }^{[4,10]}$ On the other hand, it is made from the most abundant transition metal on Earth crust, iron. Unfortunately, the bare hematite surface is catalytically very poor, and therefore requires modification with water-oxidation catalysts (WOCs) in order to extract the thermodynamic power stored when light is absorbed.
Photoelectrochemical (PEC) water splitting devices, using Earth-abundant semiconductor materials, have long been considered to be the "Holy Grail" of solar energy conversion. ${ }^{[1-9]}$

Dr. P.-Y. Tang, Dr. H.-B. Xie, Dr. M. Lira-Cantú, Prof. J. Arbiol

Catalan Institute of Nanoscience and Nanotechnology (ICN2)

CSIC and BIST

Campus UAB

Bellaterra 08193, Barcelona, Catalonia, Spain

E-mail: arbiol@icrea.cat

Dr. P.-Y. Tang, M. Biset-Peiró, Dr. Q. Shi, Dr. T. Andreu

Prof. J. R. Morante

Catalonia Institute for Energy Research (IREC)

Jardins de les Dones de Negre 1, Sant Adrià del Besòs,

Barcelona 08930, Catalonia, Spain

E-mail: jrmorante@irec.cat

The ORCID identification number(s) for the author(s) of this article can be found under https://doi.org/10.1002/aenm.201901836.
Dr. L.-J. Han, Dr. F. S. Hegner, Prof. N. López, Prof. J. R. Galán-Mascarós Institute of Chemical Research of Catalonia (ICIQ) BIST

Avinguda Països Catalans 16, Tarragona 43007, Catalonia, Spain Dr. P.-Y. Tang, Dr. P. Paciok, Dr. H.-C. Du, Dr. X.-K. Wei, Dr. L. Jin, Dr. M. Heggen, Prof. R. E. Dunin-Borkowski

Ernst Ruska-Centre for Microscopy and Spectroscopy with Electrons and Peter Grünberg Institute

Forschungszentrum Jülich $\mathrm{GmbH}$

52425 Jülich, Germany

Prof. J. R. Galán-Mascarós, Prof. J. Arbiol

ICREA

Pg. Lluís Companys 23, 08010 Barcelona, Catalonia, Spain 


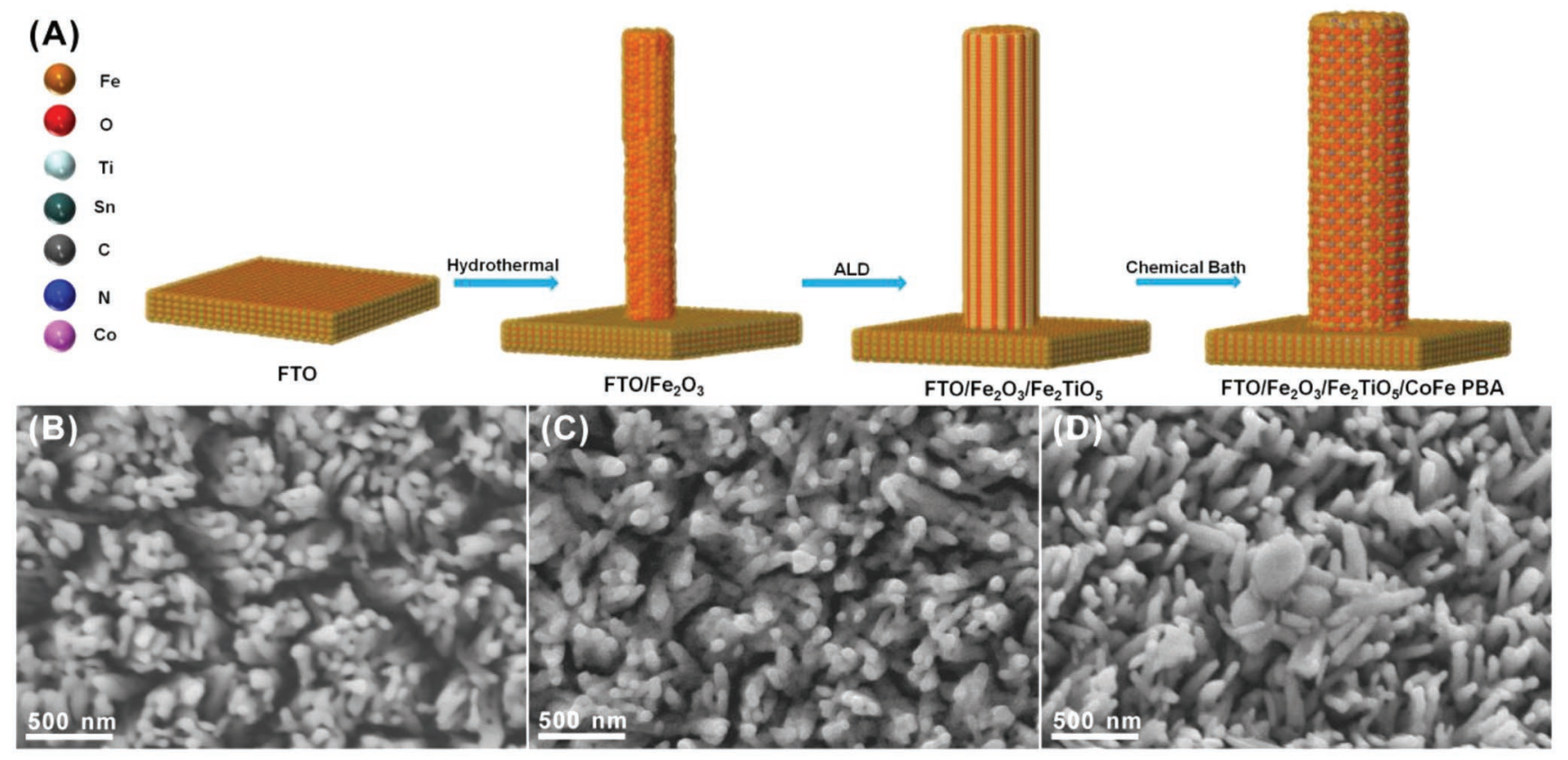

Figure 1. A) 3D Atomic supercell models with solvent accessible surface illustrating the synthetic procedure for $\mathrm{Fe}_{2} \mathrm{O}_{3} / \mathrm{Fe}_{2} \mathrm{TiO}_{5} / \mathrm{CoFe} \mathrm{PBA}$ photoanodes. SEM images of $\mathrm{B}$ ) $\left.\mathrm{Fe}_{2} \mathrm{O}_{3}, \mathrm{C}\right) \mathrm{Fe}_{2} \mathrm{O}_{3} / \mathrm{Fe}_{2} \mathrm{TiO}_{5}$, and D) $\mathrm{Fe}_{2} \mathrm{O}_{3} / \mathrm{Fe}_{2} \mathrm{TiO}_{5} / \mathrm{CoFe}$ PBA electrodes.

Regarding efficient WOCs in acidic electrolyte, many researchers have hitherto devoted their efforts to explore cheap, effective alternatives to the state-of-the-art ruthenium $(\mathrm{Ru})$ - and iridium (Ir)-based WOCs. ${ }^{[14-18]}$ For example, cobalt-containing polyoxometalates, ${ }^{[16]}$ Ti-stabilized $\mathrm{MnO}_{2},{ }^{[19]} \quad \mathrm{W}_{1-x} \mathrm{Ir}_{x} \mathrm{O}_{3-\delta},{ }^{[20]}$ $\mathrm{Ni}_{x} \mathrm{Mn}_{1-x} \mathrm{Sb}_{1.6-1.8} \mathrm{O}_{y},{ }^{[21]}$ Fe-TiO ${ }_{x},{ }^{[22]}$ iron (III) oxide, ${ }^{[23]}$ cobaltdoped hematite, ${ }^{[24]}$ and CoFe-PBA ${ }^{[25,26]}$ WOCs have been substantially explored. For a successful WOC-functionalized photoanode, it is necessary to consider the utilization of light capture of semiconductors and the catalytic effect of WOCs simultaneously, that is to say, boosting the performance of the WOCs without compromising the light absorption features. ${ }^{[11,12]} \mathrm{Up}$ to date, few reports have appeared on smart integration of hematite with WOCs, and most of them related to noble Ir-based catalysts, ${ }^{[11,27-29]}$ with which a maximum photocurrent response of $0.66 \mathrm{~mA} \mathrm{~cm}^{-2}$ at $1.23 \mathrm{~V}$ versus reversible reference electrode $(\mathrm{RHE})$ in acidic electrolyte $(\mathrm{pH}=1.01)$ was obtained. ${ }^{[11]}$ Thus, even by coupling with noble Ir-based WOCs, the photocurrent response of hematite based photoanodes in acidic electrolyte remains much lower than its theoretical value $\left(12.5 \mathrm{~mA} \mathrm{~cm}^{-2}\right) \cdot{ }^{[30]}$

Meanwhile, it is well established that the surface states present in the bandgap of hematite, mediate hole transfer and plays a vital role in determining its PEC performance. ${ }^{[31,32]}$ There are two types of surface states, intrinsic surface states derived from the loss of translational bulk crystal symmetry, and extrinsic surface states due to chemical bond formation/surface interaction with a secondary species. ${ }^{[3,34]}$ While it is difficult to completely remove intrinsic surface states, they can be modified by depositing a secondary species, ${ }^{[35]}$ which has recently been demonstrated. ${ }^{[28,36-38]}$ For instance, our previous investigation about ITO $/ \mathrm{Fe}_{2} \mathrm{O}_{3} / \mathrm{Fe}_{2} \mathrm{TiO}_{5} / \mathrm{FeNiOOH}$ photoanodes in alkaline electrolytes reveals that the surface states of hematite can be modified by atomic layer-deposited $\mathrm{Fe}_{2} \mathrm{TiO}_{5}$ and photoelectrodeposited FeNiOOH. ${ }^{[38]}$ Moreover, hematite photoanodes were combined with a CoFe-PBA resulting in enhanced photocurrent response in neutral electrolyte. ${ }^{[37]}$ Despite these observations in neutral and alkaline electrolytes, rare reports on the performance of hematite-based photoanodes in acidic media have been published, despite the extraordinary technological interest, as described above.

With the aim of designing cheap and efficient hematitebased photoanodes in acidic electrolyte, we decided to merge these two previous strategies. First, we fabricated core-shell $\mathrm{Fe}_{2} \mathrm{O}_{3} / \mathrm{Fe}_{2} \mathrm{TiO}_{5}$ type II heterostructured nanowires, as a surface-modification approach to enhance photocatalytic activity. Second, we decorated these nanowires with a nanolayer of an acid-stable WOC, the CoFe-PBA (Scheme S1, Supporting Information). These photoanodes were prepared on fluoride-doped tin oxide (FTO) glass electrodes in three steps: hydrothermal deposition of $\mathrm{Fe}_{2} \mathrm{O}_{3}$; atomic layer deposition (ALD) of $\mathrm{Fe}_{2} \mathrm{TiO}_{5}$; and finally, chemical bath deposition of CoFe-PBA, as displayed in Figure 1A. These heterostructures are able to produce the highest photocurrent response in acid media ever observed for a hematite-based photoanode, when made by scalable processes, and earth-abundant materials, opening new strategies for hematite-based PEC water splitting in acidic electrolyte.

\section{Results and Discussion}

\subsection{Processing and Structural Characterization}

Vertically aligned $\mathrm{Fe}_{2} \mathrm{O}_{3}$ nanowires with diameters ranging from 100 to $200 \mathrm{~nm}$ (Figure 1B) were first grown on a FTO substrate via a hydrothermal method. ${ }^{[38]}$ Then, a thin $\mathrm{TiO}_{2}$ 
layer was coated onto the $\mathrm{Fe}_{2} \mathrm{O}_{3}$ nanowires by 30 ALD cycles. The surface coated $\mathrm{TiO}_{2}$ was subsequently transformed into $\mathrm{Fe}_{2} \mathrm{TiO}_{5}$ through a post-sintering process in ambient atmosphere at $750{ }^{\circ} \mathrm{C}$ for $30 \mathrm{~min}$. As displayed in Figure 1C, the $\mathrm{Fe}_{2} \mathrm{O}_{3} / \mathrm{Fe}_{2} \mathrm{TiO}_{5}$ heterostructured nanowires are homogeneous without changing the nanowire-like architecture. Subsequently, the obtained $\mathrm{Fe}_{2} \mathrm{O}_{3} / \mathrm{Fe}_{2} \mathrm{TiO}_{5}$ composite nanowires were subjected to a chemical bath for $2 \mathrm{~h}$ in the presence of the CoFePBA precursor at $60{ }^{\circ} \mathrm{C}$ to produce $\mathrm{Fe}_{2} \mathrm{O}_{3} / \mathrm{Fe}_{2} \mathrm{TiO}_{5} / \mathrm{CoFe}-\mathrm{PBA}$ heterostructured nanowires. Its scanning electron microscope (SEM) image in Figure 1D reveals that the diameter of these nanowires did not change compared to the $\mathrm{Fe}_{2} \mathrm{O}_{3} / \mathrm{Fe}_{2} \mathrm{TiO}_{5}$ ones, indicating the ultrathin CoFe-PBA coating. The sample crystallinity and chemical composition were further analyzed via energy dispersive X-ray spectroscopy (EDX), X-ray photoelectron spectroscopy (XPS), and X-ray diffraction (XRD), Raman spectrum, and Fourier transform infrared (FT-IR) spectrum in Figures S1-S5 in the Supporting Information, evidencing the existence of hematite, $\mathrm{Fe}_{2} \mathrm{TiO}_{5}$, and $\mathrm{CoFe}-\mathrm{PBA}$ species in the corresponding electrodes.

The structure, crystallography, and spatial distribution of hematite, $\mathrm{Fe}_{2} \mathrm{TiO}_{5}$, and CoFe-PBA species were further investigated by aberration-corrected scanning transmission electron microscopy (AC-STEM) in high angle annular dark-field (HAADF) mode. On one hand, the HAADF STEM images of $\mathrm{Fe}_{2} \mathrm{O}_{3}$ and $\mathrm{Fe}_{2} \mathrm{O}_{3} / \mathrm{Fe}_{2} \mathrm{TiO}_{5}$ electrodes on the top and middle rows of Figure 2 show the atomic ordering of the hematite matrix. On the other hand, the $\mathrm{Fe}_{2} \mathrm{TiO}_{5}$ species in the $\mathrm{Fe}_{2} \mathrm{O}_{3} /$ $\mathrm{Fe}_{2} \mathrm{TiO}_{5}$ electrode are shown as a blurred ultrathin shell on the surface of the hematite nanowires (middle rows of Figure 2 and Figure S10, Supporting Information), in good agreement with the maps obtained by STEM combined with electron energy loss spectroscopy (EELS) in Figure S12 in the Supporting Information conducted on the same region. The additional atomic resolution HAADF STEM imaging in combination with the STEM-EELS compositional maps of the $\mathrm{Fe}_{2} \mathrm{O}_{3}$ and $\mathrm{Fe}_{2} \mathrm{O}_{3} / \mathrm{Fe}_{2} \mathrm{TiO}_{5}$ electrodes are included in Figures S6-S12 in the Supporting Information, confirming the core-shell nanowires structure of the $\mathrm{Fe}_{2} \mathrm{O}_{3} / \mathrm{Fe}_{2} \mathrm{TiO}_{5}$ electrode. Notably, coordination polymers are especially susceptible to the electron beam damage, hindering stable atomic-level HAADF STEM observation of the CoFe-PBA. ${ }^{[25,38-41]}$ Thus, we employed bright field HRTEM to monitor the surface structure evolution of the $\mathrm{Fe}_{2} \mathrm{O}_{3} / \mathrm{Fe}_{2} \mathrm{TiO}_{5} / \mathrm{CoFe}-\mathrm{PBA}$ electrodes.

Figure 2A displays a representative TEM image of a $\mathrm{Fe}_{2} \mathrm{O}_{3} /$ $\mathrm{Fe}_{2} \mathrm{TiO}_{5} / \mathrm{CoFe}-\mathrm{PBA}$ nanowire. According to Figure 2B-D, the nanoparticles attached to the composite nanowire can be assigned to CoFe-PBA species. The hematite and $\mathrm{Fe}_{2} \mathrm{TiO}_{5}$ phases dominate the nanowires matrix, as identified by the HRTEM and its corresponding power spectrum in Figure 2E-F. Moreover, the corresponding frequency filtered image (Figure 2G) clearly illustrates the presence of a localized hematite nanowire core and an ultrathin pseudo-brookite shell. Figure 2E and Figure S13 in the Supporting Information show that the fine CoFe-PBA shell on the nanowires surface tends to possess an amorphous structure, whereas bigger CoFe-PBA nanoparticles present lattice fringes denoting its good crystallinity, as displayed in Figure 2C and Figure S14 in the Supporting Information.
The spatial elemental distribution of $\mathrm{Fe}_{2} \mathrm{O}_{3} / \mathrm{Fe}_{2} \mathrm{TiO}_{5} / \mathrm{CoFe}$ PBA electrodes was further characterized via HAADF STEM combined with EELS. In addition to the elemental signals from the CoFe-PBA nanoparticles, we also found the presence of $\mathrm{C}, \mathrm{N}, \mathrm{O}, \mathrm{Co}$, and $\mathrm{Fe}$ surrounding the nanowire matrix in the STEM-EELS maps shown in Figure 3 and Figures S15-S16 in the Supporting Information. ${ }^{[25]}$ These results evidence that the surface amorphous region observed in Figure $2 \mathrm{E}$ is indeed an ultrathin CoFe-PBA shell at the surface of the $\mathrm{Fe}_{2} \mathrm{O}_{3} / \mathrm{Fe}_{2} \mathrm{TiO}_{5}$ nanowires. Additionally, the statistical diameter size distributions of $\mathrm{Fe}_{2} \mathrm{O}_{3}, \mathrm{Fe}_{2} \mathrm{O}_{3} / \mathrm{Fe}_{2} \mathrm{TiO}_{5}$, and $\mathrm{Fe}_{2} \mathrm{O}_{3} / \mathrm{Fe}_{2} \mathrm{TiO}_{5} / \mathrm{CoFe}$ PBA nanowires in Figure S17 in the Supporting Information reveal that $\mathrm{Fe}_{2} \mathrm{O}_{3}, \mathrm{Fe}_{2} \mathrm{O}_{3} / \mathrm{Fe}_{2} \mathrm{TiO}_{5}, \mathrm{Fe}_{2} \mathrm{O}_{3} / \mathrm{Fe}_{2} \mathrm{TiO}_{5} / \mathrm{CoFe}$ PBA nanowires have average diameter size of $168 \pm 43,174 \pm 63$, and $185 \pm 70 \mathrm{~nm}$, respectively. The average diameter size of these nanowires did not significantly change with the coating of $\mathrm{Fe}_{2} \mathrm{TiO}_{5}$ and CoFe PBA, which is consistent with the SEM results.

\subsection{Photoelectrochemical Performance}

The detailed PEC performance measured for these photoanodes is displayed in Figure 4. Cyclic voltammtry (CV) measurements in the dark (Figure 4A) show a positive shift of the onset potential of hematite upon coating with the ultrathin $\mathrm{Fe}_{2} \mathrm{TiO}_{5}$ shell, consistent with our previous work, ${ }^{[38]}$ whereas modification with CoFe-PBA reduces the onset potential of the $\mathrm{Fe}_{2} \mathrm{O}_{3} / \mathrm{Fe}_{2} \mathrm{TiO}_{5}$ electrode, which demonstrates the positive catalytic effect of CoFe-PBA. Under light irradiation, the $\mathrm{CV}$ in Figure 4B and the statistical data in Figure S18 in the Supporting Information reveal that pristine $\mathrm{Fe}_{2} \mathrm{O}_{3}$ electrodes exhibit a very low photocurrent response of $0.12 \mathrm{~mA} \mathrm{~cm}^{-2}$ at $1.23 \mathrm{~V}$ versus RHE, the thermodynamic potential for the oxygen evolution reaction. ${ }^{[42]}$ Upon $\mathrm{Fe}_{2} \mathrm{TiO}_{5}$ deposition, the photocurrent density increases significantly above $1.0 \mathrm{~V}$ versus RHE, reaching $0.90 \mathrm{~mA} \mathrm{~cm}^{-2}$ at $1.23 \mathrm{~V}$ versus RHE (Figure 4B). The onset potential is further improved for the $\mathrm{Fe}_{2} \mathrm{O}_{3} / \mathrm{Fe}_{2} \mathrm{TiO}_{5} / \mathrm{CoFe}-$ PBA electrode. This parameter was used to optimize the $\mathrm{Fe}_{2} \mathrm{O}_{3} /$ $\mathrm{Fe}_{2} \mathrm{TiO}_{5} / \mathrm{CoFe}-\mathrm{PBA}$ processing (Figures S19-S20, Supporting Information). According to the statistical data in Figure S19 in the Supporting Information, we reached a maximum PEC performance with electrodes coated with CoFe-PBA by a chemical bath reaction at $60{ }^{\circ} \mathrm{C}$ for $2 \mathrm{~h}$, giving $1.25 \mathrm{~mA} \mathrm{~cm}{ }^{-2}$ at $1.23 \mathrm{~V}$ versus RHE. To the best of our knowledge, this is the highest photocurrent value observed for hematite-based photoanodes in acidic electrolyte (see Table S1, Supporting Information). Moreover, it is better than the photocurrent response for $\mathrm{Fe}_{2} \mathrm{O}_{3} / \mathrm{Fe}_{2} \mathrm{TiO}_{5}\left(0.90 \mathrm{~mA} \mathrm{~cm}{ }^{-2}\right.$, Figure 4B) and $\mathrm{Fe}_{2} \mathrm{O}_{3} / \mathrm{CoFe}-\mathrm{PBA}$ $\left(0.62 \mathrm{~mA} \mathrm{~cm}^{-2}\right.$, based on the statistical data in Figures S21-S22, Supporting Information) electrodes indicating a synergic effect in combining core-shell $\mathrm{Fe}_{2} \mathrm{O}_{3} / \mathrm{Fe}_{2} \mathrm{TiO}_{5}$ type II heterojunction with the CoFe-PBA WOC.

The chopped light photocurrent-potential curves in Figure 4C show smaller photocurrent transients for the $\mathrm{Fe}_{2} \mathrm{O}_{3} / \mathrm{Fe}_{2} \mathrm{TiO}_{5} /$ CoFe-PBA electrodes, in particular in the potential range of 1.21.7 $\mathrm{V}$ versus RHE. This reduction of the photocurrent transient indicates that the electron-hole recombination is suppressed by the $\mathrm{Fe}_{2} \mathrm{TiO}_{5}$ and $\mathrm{CoFe}-\mathrm{PBA}$ modification, further demonstrating 


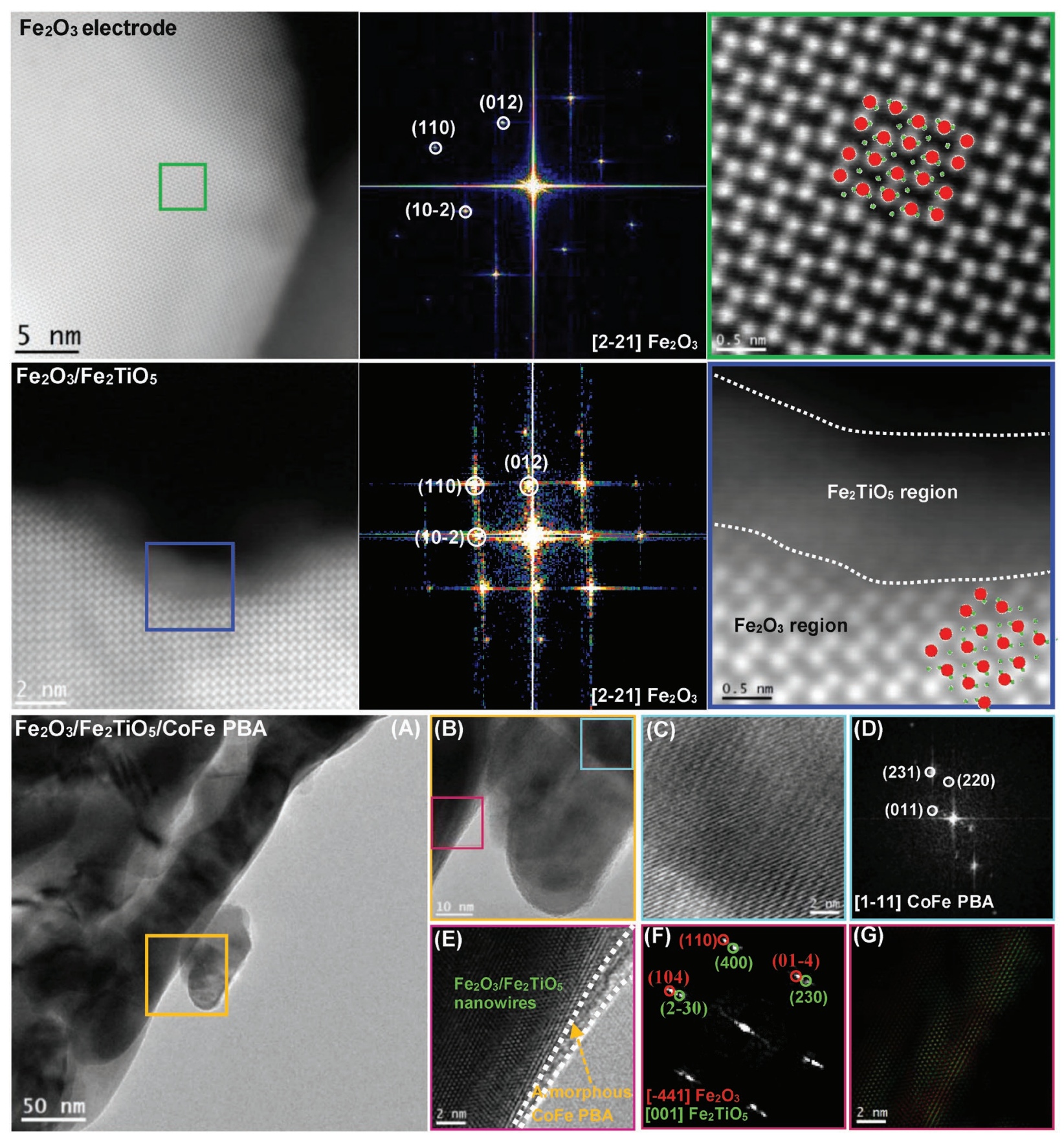

Figure 2. Top row: (Left) HAADF STEM image showing the atomic ordering at the edge region of the $\mathrm{Fe}_{2} \mathrm{O}_{3}$ electrode. (Middle) the corresponding colored fast Fourier transform power spectrum (FFT) indicates that the nanowires crystallize in the hematite phase as visualized along the [2-21] direction. (Right) Atomic resolution HAADF STEM image of the green squared region showing the ordering of $\mathrm{Fe}$, while $\mathrm{O}$ atoms are almost not visible in HAADF STEM mode due to the their weak Z-contrast. Middle row: (Left) HAADF STEM image showing the atomic ordering at the edge region of the $\mathrm{Fe}_{2} \mathrm{O}_{3} / \mathrm{Fe}_{2} \mathrm{TiO}_{5}$ electrode. (Middle) The corresponding colored FFT spectrum indicates that the nanowires matrix is hematite as visualized along the [2-21] direction. (Right) Atomic resolution HAADF STEM image of the blue squared region showing the typical ordering of Fe atoms in hematite. The $\mathrm{Fe}_{2} \mathrm{TiO}_{5}$ shell is observed as a blurred ultrathin shell $(\approx 1 \mathrm{~nm})$ on the surface of the hematite matrix since the heights of hematite-core and $\mathrm{Fe}_{2} \mathrm{TiO}_{5}$ shell are different. (the inset shows the atomic model of $\mathrm{Fe}$ and $\mathrm{O}$ atoms visualized from the [2-21] direction, with $\mathrm{Fe}$ atoms marked as red and $\mathrm{O}$ atoms marked as green). Bottom row: A) low magnification bright field TEM images showing the general morphology of the $\mathrm{Fe}_{2} \mathrm{O}_{3} / \mathrm{Fe}_{2} \mathrm{TiO}_{5} / \mathrm{CoFe}_{\mathrm{O}} \mathrm{PBA}$ nanowires. B) HRTEM detail showing the yellow squared interface area in (A). C) Magnified HRTEM detail of the selected surface nanoparticle and D) corresponding power spectrum indicating that the nanoparticle attached to the nanowire matrix crystallized in the cubic CoFe-PBA phase, as visualized along the [1-11] direction. E) HRTEM image of the nanowire surface region squared in purple in (B). The white dotted line is marking an amorphous CoFe-PBA region. F) Corresponding FFT spectrum indicating that the nanowire heterostructure is mainly composed of hematite and pseudobrookite as visualized along the [-441] and [001] directions, respectively. G) Frequency filtered structural map of the hematite (red) and pseudobrookite (green), showing their atomic stack sequence. 

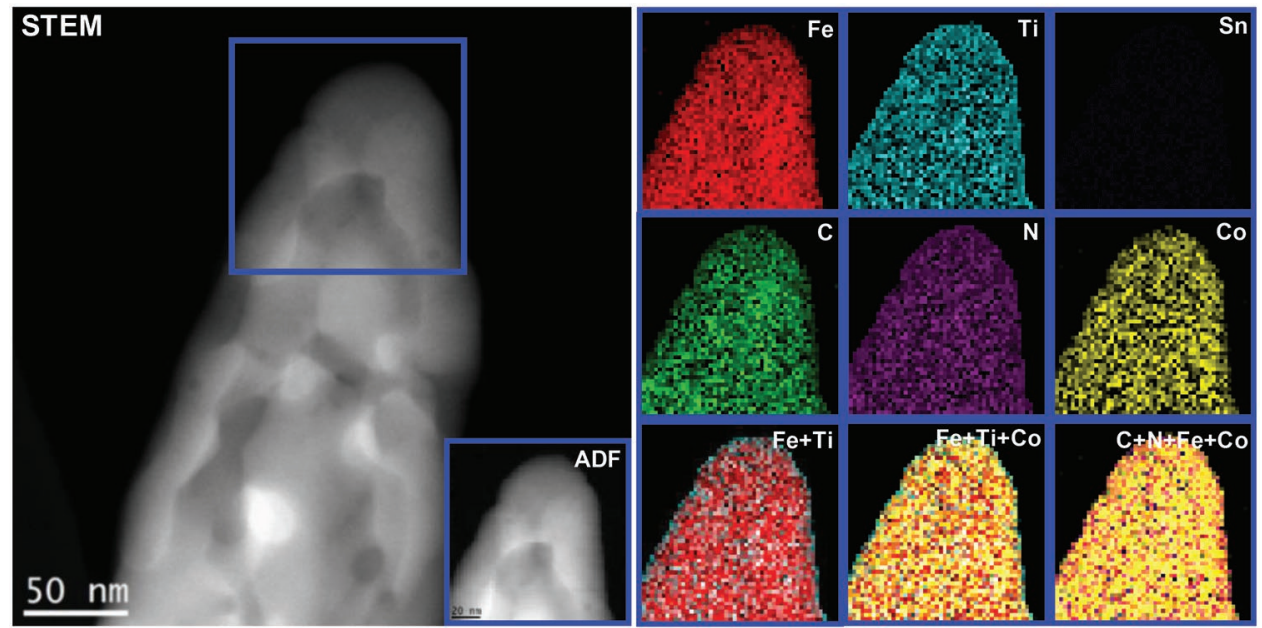

Figure 3. High magnification EELS chemical composition maps obtained from the blue rectangle area in the ADF-STEM micrograph of a nanowire extracted from the $\mathrm{Fe}_{2} \mathrm{O}_{3} / \mathrm{Fe}_{2} \mathrm{TiO}_{5} / \mathrm{CoFe}-\mathrm{PBA}$ electrode. Individual $\mathrm{Fe}$ (red), $\mathrm{C}$ (green), $\mathrm{Sn}$ (blue), $\mathrm{N}$ (purple), Ti (indigo), and Co (yellow) maps and their composites.

its advantage. Moreover, the UV-vis absorptance, Tauc plots, IPCE, and APCE spectra of the $\mathrm{Fe}_{2} \mathrm{O}_{3}, \mathrm{Fe}_{2} \mathrm{O}_{3} / \mathrm{Fe}_{2} \mathrm{TiO}_{5}$, and $\mathrm{Fe}_{2} \mathrm{O}_{3} / \mathrm{Fe}_{2} \mathrm{TiO}_{5} / \mathrm{CoFe}$ PBA electrodes in Figure $\mathrm{S} 23$ in the Supporting Information further evidence that the enhanced PEC performance of $\mathrm{Fe}_{2} \mathrm{O}_{3} / \mathrm{Fe}_{2} \mathrm{TiO}_{5} / \mathrm{CoFe}-\mathrm{PBA}$ electrodes is attributed to the synergetic effect from $\mathrm{Fe}_{2} \mathrm{TiO}_{5}$ and $\mathrm{CoFe}-\mathrm{PBA}$.

The PEC stability of these three electrodes was investigated by chronoamperometry at a constant applied working potential of $1.23 \mathrm{~V}$ versus RHE (Figure 4D) at $\mathrm{pH}=1$ for $24 \mathrm{~h}$. The photocurrent response of $\mathrm{Fe}_{2} \mathrm{O}_{3}$ electrodes shows a slow but continuous decrease, maintaining about $40 \%$ of the initial photocurrent response after $24 \mathrm{~h}$ test. In contrast, $\mathrm{Fe}_{2} \mathrm{O}_{3} /$ $\mathrm{Fe}_{2} \mathrm{TiO}_{5}$ and $\mathrm{Fe}_{2} \mathrm{O}_{3} / \mathrm{Fe}_{2} \mathrm{TiO}_{5} / \mathrm{CoFe}-\mathrm{PBA}$ electrodes follow a similar trend, showing an initial drop in photocurrent during the first $2 \mathrm{~h}$ and show no further sign of fatigue during the rest of the stability measurement, retaining around $80 \%$ of the initial photocurrent response after $24 \mathrm{~h}$ test. Additionally, we monitored the evolved oxygen in the case of $\mathrm{Fe}_{2} \mathrm{O}_{3} / \mathrm{Fe}_{2} \mathrm{TiO}_{5} / \mathrm{CoFe}-$ PBA electrodes by a calibrated Fibox $\mathrm{O}_{2}$ detector in a gastight cell during the first $2 \mathrm{~h}$ water oxidation at $1.23 \mathrm{~V}$ versus RHE (Figure S24A, Supporting Information). The theoretical oxygen yield was calculated from the total charge passed during PEC water oxidation. Faradaic Efficiencies above 94\% were demonstrated (Figure S24B, Supporting Information), indicating that the photocurrent response is mainly originating from the water oxidation process. The enhanced stability of $\mathrm{Fe}_{2} \mathrm{O}_{3} /$ $\mathrm{Fe}_{2} \mathrm{TiO}_{5}$ and $\mathrm{Fe}_{2} \mathrm{O}_{3} / \mathrm{Fe}_{2} \mathrm{TiO}_{5} / \mathrm{CoFe}-\mathrm{PBA}$ electrodes compared to $\mathrm{Fe}_{2} \mathrm{O}_{3}$ electrodes is further confirmed by the CV curves of these electrodes after $24 \mathrm{~h}$ stability test in Figure S25 in the Supporting Information. Moreover, the SEM images of $\mathrm{Fe}_{2} \mathrm{O}_{3}$ electrodes after $24 \mathrm{~h}$ stability measurement in Figure S26A-C in the Supporting Information reveal that the attenuation of the photocurrent response in $\mathrm{Fe}_{2} \mathrm{O}_{3}$ electrodes is derived from its nanowires structure degradation in acidic electrolyte. In contrast, the degradation of $\mathrm{Fe}_{2} \mathrm{O}_{3} / \mathrm{Fe}_{2} \mathrm{TiO}_{5}$, and $\mathrm{Fe}_{2} \mathrm{O}_{3} / \mathrm{Fe}_{2} \mathrm{TiO}_{5} /$ CoFe-PBA electrodes' nanowires are substantially suppressed, as displayed in Figure S26D-I in the Supporting Information. Therefore, we assign the drastically enhanced stability of $\mathrm{Fe}_{2} \mathrm{O}_{3} / \mathrm{Fe}_{2} \mathrm{TiO}_{5} / \mathrm{CoFe}-\mathrm{PBA}$ electrodes to the dual protective effect provided by the $\mathrm{Fe}_{2} \mathrm{TiO}_{5}$ and the CoFe-PBA (Figure 4E), both of which are stable in acidic electrolytes. ${ }^{[19,22,25,43]}$

\subsection{Mechanistic Investigation via Photoelectrochemical Impedance Spectroscopy (PEIS)}

It is well established that the catalytic activity of photoanodes is strongly dependent on the characteristics of the surface states at the semiconductor-electrolyte interface (SEI). ${ }^{[4-46]}$ While those surface states can limit water oxidation kinetics by acting as electron-hole recombination centers, they can also have a beneficial influence on water oxidation, promoting electron transfer across the interface, dependent on their respective kinetics. ${ }^{[47]}$ In particular, electrical active surface states presented in the hematite bandgap are supposed to play a vital role in PEC water oxidation; thus, a deeper investigation is required to probe their effect on charge transfer at the SEI (Figure 4E). ${ }^{38,48-51]}$

We employed CV and PEIS techniques to monitor the evolution of such surface states in hematite, ${ }^{[44,45]}$ which was suggested to be an iron-oxo intermediate by operando IR spectroscopy ${ }^{[48]}$ and density functional theory calculations ${ }^{[52,53]}$ and how it is influenced by successive $\mathrm{Fe}_{2} \mathrm{TiO}_{5}$ and $\mathrm{CoFe}-\mathrm{PBA}$ deposition. As displayed in Figure 5A, the precatalytic feature in the $\mathrm{CV}$, which is related to adding and removing electrons to/from the surface states, changes with the addition of $\mathrm{Fe}_{2} \mathrm{TiO}_{5}$ and CoFe-PBA. ${ }^{[48]}$ Their significant impact on the surface states was further suggested by PEIS. The equivalent circuits in Figure S29 in the Supporting Information were used to fit the obtained data in Figures S27-S28 in the Supporting Information; the obtained resistances and capacitances are shown in Figures S30-S31 in the Supporting Information.

From the fitted surface states or trap capacitance $C_{\text {trap }}$, we estimated the density of surface states (DOSS) with Equation $(1)^{[32,36,54,55]}$

$N_{\mathrm{SS}}(E)=\frac{C_{\text {trap }}(E)}{q}$ 

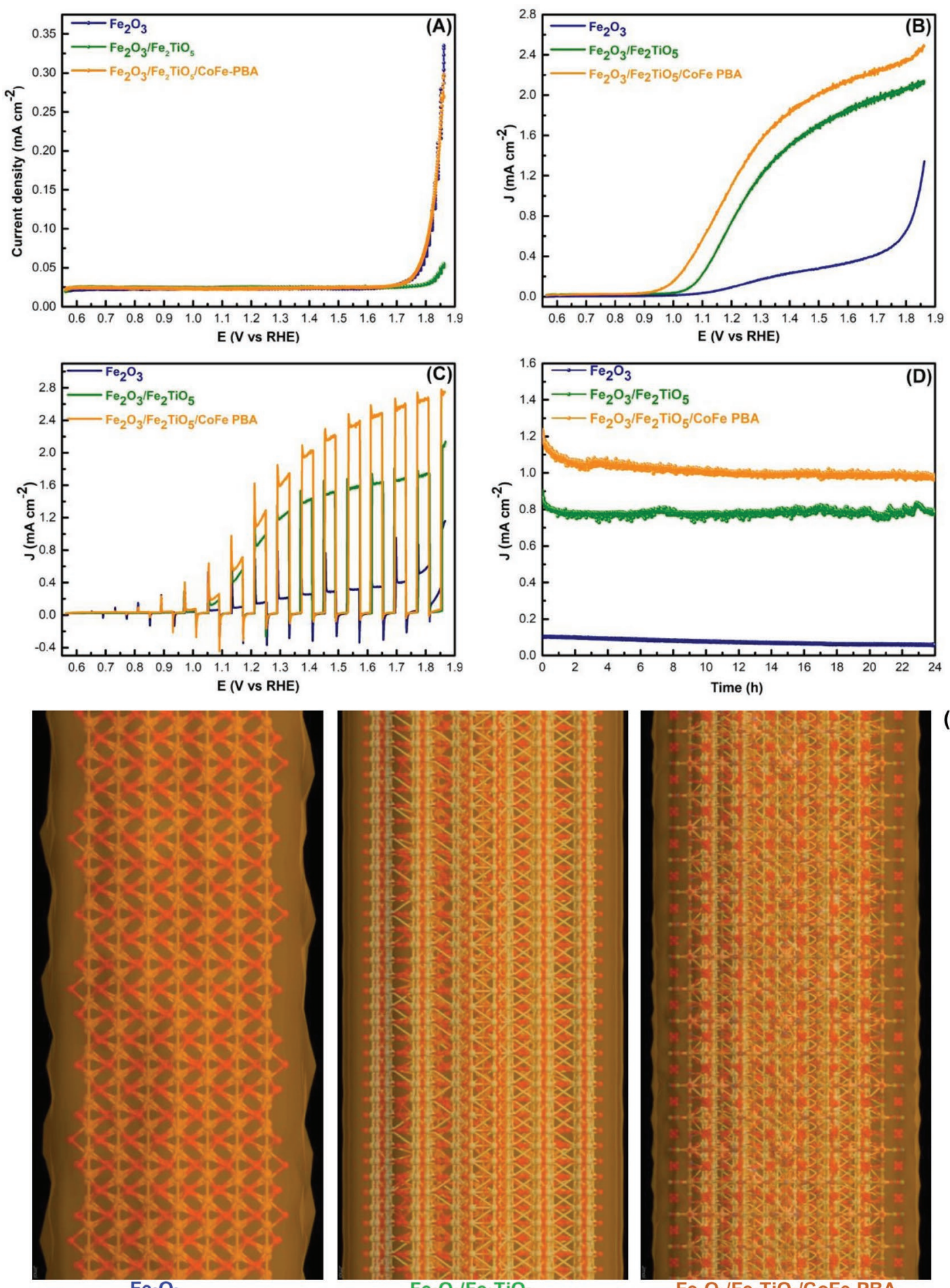

(E)

$\mathrm{Fe}_{2} \mathrm{O}_{3}$

$\mathrm{Fe}_{2} \mathrm{O}_{3} / \mathrm{Fe}_{2} \mathrm{TiO}_{5}$

$\mathrm{Fe}_{2} \mathrm{O}_{3} / \mathrm{Fe}_{2} \mathrm{TiO}_{5} / \mathrm{CoFe} \mathrm{PBA}$

Figure 4. A) Cyclic voltammetry under dark, B) cyclic voltammetry under illumination, C) chopped light photocurrent-potential curves, and D) photoelectrochemical stability test operated at $1.23 \mathrm{~V}$ versus RHE of the $\mathrm{Fe}_{2} \mathrm{O}_{3}, \mathrm{Fe}_{2} \mathrm{O}_{3} / \mathrm{Fe}_{2} \mathrm{TiO}_{5}$, and $\mathrm{Fe}_{2} \mathrm{O}_{3} / \mathrm{Fe}_{2} \mathrm{TiO}_{5} / \mathrm{CoFe}$-PBA electrodes for $24 \mathrm{~h}$. All polarization potentials reported here are relative to the RHE, and current densities are based on the geometric area. $J\left(\mathrm{~mA} \mathrm{~cm}^{-2}\right)$ represents the current density response under light illumination. E) Zoom in view of the atomic supercell model with solvent accessible surface of $\mathrm{Fe}_{2} \mathrm{O}_{3}, \mathrm{Fe}_{2} \mathrm{O}_{3} / \mathrm{Fe}_{2} \mathrm{TiO}_{5}$, and $\mathrm{Fe}_{2} \mathrm{O}_{3} /$ $\mathrm{Fe}_{2} \mathrm{TiO}_{5} / \mathrm{CoFe}-\mathrm{PBA}$ nanowires show the modified surface interfaces.

where $N_{\mathrm{sS}}(\mathrm{E})$ is the DOSS $\left(\mathrm{cm}^{-2} \mathrm{eV}^{-1}\right)$ as a function of the applied potential and $q$ is the electron charge $\left(1.602 \times 10^{-19} \mathrm{C}\right)$. As shown in Figure $5 \mathrm{~B}$, the energy and density distribution of the surface states $N_{\mathrm{ss}}^{[32,54]}$ follows the order $\mathrm{Fe}_{2} \mathrm{O}_{3}<\mathrm{Fe}_{2} \mathrm{O}_{3} /$ $\mathrm{Fe}_{2} \mathrm{TiO}_{5}<\mathrm{Fe}_{2} \mathrm{O}_{3} / \mathrm{Fe}_{2} \mathrm{TiO}_{5} / \mathrm{CoFe}-\mathrm{PBA}$ across the entire surface states dominated region (0.86 to $1.46 \mathrm{~V})$. The extended 

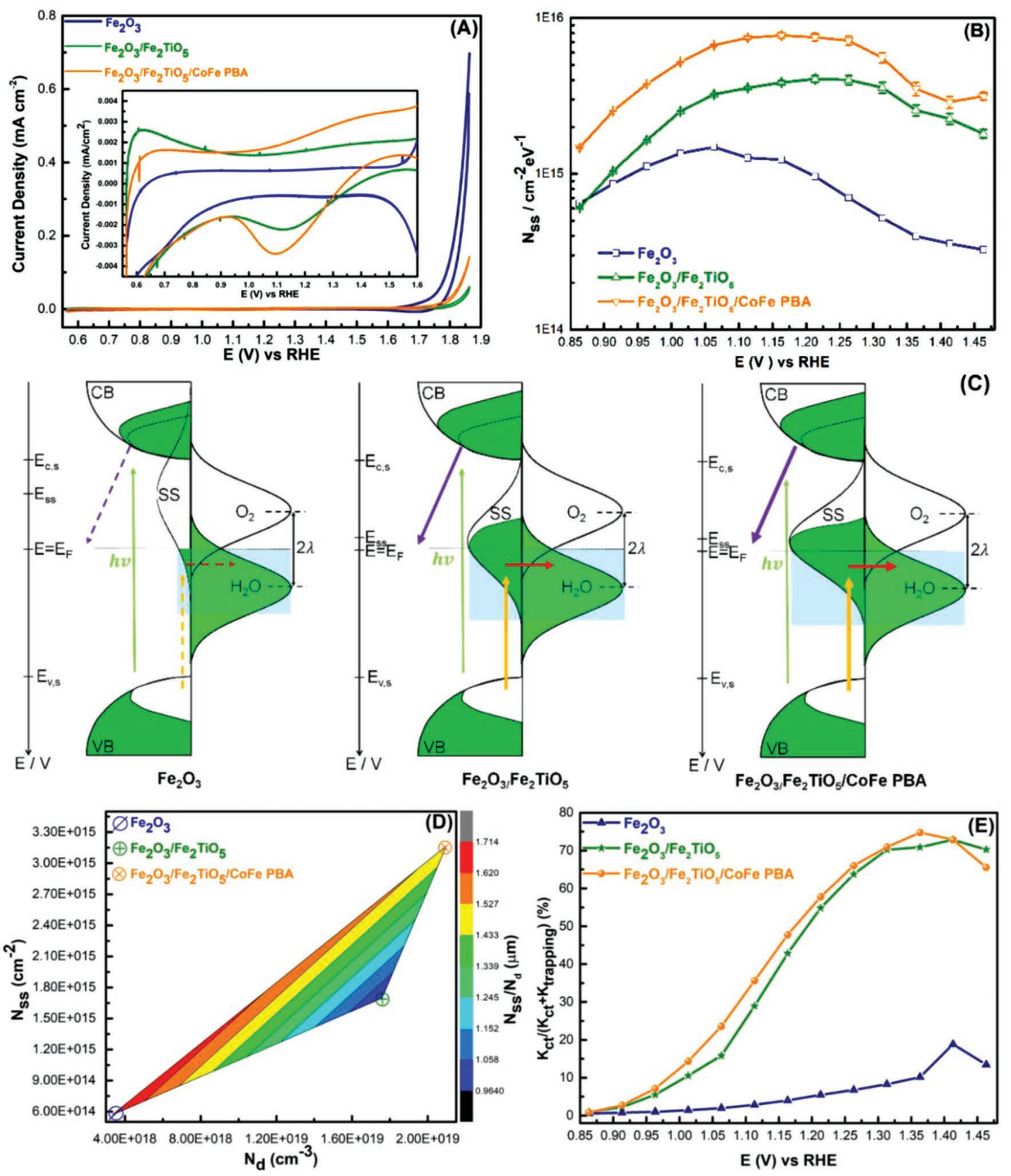

Figure 5. A) CV curves scanned immediately in dark at $20 \mathrm{mV} \mathrm{s}^{-1}$ after holding the electrode potential at $1.85 \mathrm{~V}$ versus RHE for 1 min under illumination (the inset shows its magnified plot). B) DOSS as a function of the applied potential. Error bars stem from the goodness of the EIS data fittings. C) Kinetic scheme of the charge generation and transfer processes at the SEI at 1.23 V versus RHE under illumination of these electrodes. Green and white areas represent electron filled and empty states, respectively. The dotted lines marked region in the CB filled states refer to photogenerated electrons with the same relative area as the empty states at the VB; the exceeding green regions highlight the doping levels in these electrodes. The green arrows denote the charge generation process upon photons absorption; the yellow arrows denote the hole trapping process at SS (surface states); the red arrows denote the hole transfer process from the SS to the electrolyte; the purple arrows denote electron transfer from CB states to the FTO substrates. The thickness and shape of the arrows reveal the relative rates of the charge transfer processes, where the dotted lines mean the slowest rate $\left(\mathrm{Fe}_{2} \mathrm{O}_{3}\right.$ electrode $)$ and the thickest lines means the fastest rate $\left(\mathrm{Fe}_{2} \mathrm{O}_{3} / \mathrm{Fe}_{2} \mathrm{TiO}_{5} / \mathrm{CoFe}-\mathrm{PBA}\right.$ electrode). The light indigo shaded areas refer to the relative overlapping of the DOSS and water density of states. $E$ : electrode potential; $E_{c, s}$ : surface CB edge potential; $E_{F}$ : Fermi level of the semiconductors that matches the electrode potential E) and the $\mathrm{O}_{2} / \mathrm{H}_{2} \mathrm{O}$ couple's thermodynamic potential (1.23 V vs RHE); $E_{S S}$ : center potential of the SS distribution; $E_{\mathrm{v}, s}$ : surface VB edge potential; $\lambda$ : redox couple reorganization energy. It is worth noting that the relative size of the DOSS distribution for these electrodes has been intentionally enlarged to highlight the SS. D): Total surface state density $\left(N_{\mathrm{ss}}\right)$, donor density $\left(N_{\mathrm{d}}\right)$, and their ratio $\left(N_{\mathrm{ss}} / N_{\mathrm{d}}\right)$ plot. $N_{\mathrm{d}}$ was estimated from the slopes of the Mott-Schottky plots (Figure S30, Supporting Information), whereas $N_{s s}$ was obtained from integration of the DOSS profiles. Color bar with a unit of $\mu \mathrm{m}$ is plotted at the right $Y$ axis for $N_{\mathrm{ss}} / N_{\mathrm{d}}$. E) Ratio of the charge transfer rate constant $\left(k_{\mathrm{ct}}\right)$ and the sum of $k_{\mathrm{ct}}$ and trapping rate constant $\left(k_{\text {trapping }}\right)$ at different potentials. 
surface states distribution from 0.86 to $1.46 \mathrm{~V}$ in unmodified $\mathrm{Fe}_{2} \mathrm{O}_{3}$ electrodes probably spans inside the $\mathrm{CB}$, where recombination with $\mathrm{CB}$ electrons may occur. Moreover, it triggers a deleterious Fermi level pinning, which also contributes to its low photocurrent response. ${ }^{[54]}$ Upon surface modification, the DOSS maximum shifts to more positive potentials, i.e., further into the bandgap, which minimizes overlap with the conduction band (Figure 5C). Further, its shape coincides well with the cathodic CV curves obtained after holding the electrodes at a potential of $1.85 \mathrm{~V}$ versus RHE for $1 \mathrm{~min}$ (Figure $5 \mathrm{~A}$ ), which also indicates the correct utilization of the equivalent circuit model for PEIS fitting. ${ }^{[44,48]}$ Consequently, the ultrathin $\mathrm{Fe}_{2} \mathrm{TiO}_{5}$ and CoFe-PBA coatings indeed work together modifying the density and energy level of the surface states in hematite photoanodes.

Assuming surface states mediated charge-transfer (CT), the CT rate constant $\left(k_{\mathrm{ct}}\right)$ at a certain electrode polarization potential $(E)$, is proportional to Equation $(2)^{[28,32,54-56]}$

$k_{\mathrm{ct}} \propto \int_{\mathrm{E}_{\mathrm{v} s}}^{\mathrm{E}} N_{\mathrm{ss}} f(E) D_{\mathrm{H}_{2} \mathrm{O}}(E) \mathrm{d} E$

in which $f(E)$ is the Fermi-Dirac distribution indicating the fraction of occupied surface states and $D_{\mathrm{H} 2 \mathrm{O}}(E)$ is the water density of states $\left(\mathrm{cm}^{-2} \mathrm{eV}^{-1}\right)$. Given that the inelastic hole trapping process mediated by surface states is fast enough, ${ }^{[53]}$ the photocurrent response is proportional to $k_{\mathrm{ct}}{ }^{[57]}$ depending on the overlap between the filled surface states and the filled water density of states. There is, thus, a direct correlation between the percentage of available filled surface states (larger DOSS) near the thermodynamic potential for water oxidation and the observed photocurrent response at $1.23 \mathrm{~V}$ versus RHE because of the required isoenergetic hole transfer process at the SEI. ${ }^{[38,54,55]}$ As illustrated in Figure $5 \mathrm{C}$, the $\mathrm{Fe}_{2} \mathrm{O}_{3} / \mathrm{Fe}_{2} \mathrm{TiO}_{5} /$ CoFe-PBA electrode possesses the highest photocurrent response at $1.23 \mathrm{~V}$ versus RHE due to the maximum energy level matching between the surface states of the photoanodes and the water density of states.

Furthermore, a combined comparison of the $N_{\mathrm{ss}}, N_{\mathrm{d}}$, and $N_{\mathrm{sS}} / N_{\mathrm{d}}$ ratio is presented in Figure 5D. The pristine $\mathrm{Fe}_{2} \mathrm{O}_{3}$ electrodes present a relatively high $N_{\mathrm{ss}} / N_{\mathrm{d}}$ ratio but poor PEC performance, indicating that a large $N_{\mathrm{ss}} / N_{\mathrm{d}}$ ratio does not guarantee a good photocurrent response due to the lack of donors and low electrical conductivity. For the $\mathrm{Fe}_{2} \mathrm{O}_{3} / \mathrm{Fe}_{2} \mathrm{TiO}_{5}$ electrodes, the $N_{\mathrm{d}}$ is promoted via Ti doping, and this enables a higher photocurrent. In the case of the $\mathrm{Fe}_{2} \mathrm{O}_{3} / \mathrm{Fe}_{2} \mathrm{TiO}_{5} / \mathrm{CoFe}$ PBA electrode, $N_{\mathrm{ss}}$ and $N_{\mathrm{d}}$ are both numerous enough to further increase the photocurrent response.

The charge transfer efficiency at the SEI is first estimated by Equation $(3)^{[33,54,57,58]}$

Transfer efficiency $(\%)=\frac{k_{\mathrm{ct}}}{k_{\mathrm{ct}}+k_{\text {trapping }}}=\frac{R_{\text {trapping }}}{R_{\mathrm{ct} \text {,trap }}+R_{\text {trapping }}}$

where $k_{\mathrm{ct}}$ and $k_{\text {trapping }}$ are the charge transfer and trapping rate constants, respectively, and $R_{\mathrm{ct}}$ and $R_{\text {trapping }}$ are the corresponding resistances. The calculated charge transfer efficiency from PEIS is shown in Figure 5E. In the case of the $\mathrm{Fe}_{2} \mathrm{O}_{3} / \mathrm{Fe}_{2} \mathrm{TiO}_{5} / \mathrm{CoFe}-\mathrm{PBA}$ electrode, over $60 \%$ of the holes are transferred into the electrolyte at $1.23 \mathrm{~V}$ versus RHE, which is almost 10 times as high as for pristine $\mathrm{Fe}_{2} \mathrm{O}_{3}$. Additionally, the calculated charge transfer efficiency of these electrodes is in good agreement with the steady-state current-voltage relationship (Figure 4B) and the charge separation efficiencies (Figure S32, Supporting Information) of $\mathrm{Fe}_{2} \mathrm{O}_{3}, \mathrm{Fe}_{2} \mathrm{O}_{3} / \mathrm{Fe}_{2} \mathrm{TiO}_{5}$ and $\mathrm{Fe}_{2} \mathrm{O}_{3} / \mathrm{Fe}_{2} \mathrm{TiO}_{5} / \mathrm{CoFe}-\mathrm{PBA}$ electrodes obtained via comparing the cyclic voltammetry measurements in electrolyte with and without a hole scavenger, further confirming the highest charge transfer efficiency of the $\mathrm{Fe}_{2} \mathrm{O}_{3} / \mathrm{Fe}_{2} \mathrm{TiO}_{5} / \mathrm{CoFe}-\mathrm{PBA}$ electrodes. ${ }^{[32]}$

\section{Conclusion}

In summary, we have successfully integrated $\mathrm{Fe}_{2} \mathrm{O}_{3}$ nanowires with an ultrathin $\mathrm{Fe}_{2} \mathrm{TiO}_{5}$ heterojunction and $\mathrm{CoFe}-\mathrm{PBA}$ decoration for enhanced $\mathrm{PEC}$ water splitting in acidic electrolyte $(\mathrm{pH}=1)$. Thanks to the combination of core-shell $\mathrm{Fe}_{2} \mathrm{O}_{3} /$ $\mathrm{Fe}_{2} \mathrm{TiO}_{5}$ type II heterojunction nanowires and the catalytic function of CoFe-PBA, $\mathrm{Fe}_{2} \mathrm{O}_{3} / \mathrm{Fe}_{2} \mathrm{TiO}_{5} / \mathrm{CoFe}-\mathrm{PBA}$ composite photoanodes are able to deliver $1.25 \mathrm{~mA} \mathrm{~cm}^{-2}$ photocurrent at $1.23 \mathrm{~V}$ versus RHE, almost one order of magnitude photocurrent increment in comparison to the pristine $\mathrm{Fe}_{2} \mathrm{O}_{3}$ nanowires. By a systematic electrochemical investigation, the enhanced PEC performance of the $\mathrm{Fe}_{2} \mathrm{O}_{3} / \mathrm{Fe}_{2} \mathrm{TiO}_{5} / \mathrm{CoFe}$-PBA composite electrode can be attributed to the modified surface states density after successive coatings, as well as the enhanced donor density derived from inevitable Ti doping during the high temperature sintering. ${ }^{[38]}$ This work suggests that simultaneously employing the synergy of core-shell $\mathrm{Fe}_{2} \mathrm{O}_{3} / \mathrm{Fe}_{2} \mathrm{TiO}_{5}$ type II heterojunction and CoFe-PBA WOCs could be an effective approach to improve the PEC performance of photoanodes in acidic electrolytes, bringing new promise toward effective solar-fuel generation.

\section{Experimental Section}

Chemicals and Materials: All chemical reagents were purchased from Sigma-Aldrich and used without further purification. All solutions were prepared with Milli-Q water $(\approx 18.2 \mathrm{M} \Omega \mathrm{cm}$ resistivity). FTO substrate (735167-1EA, $7 \Omega \mathrm{sq}^{-1}$ ) was purchased from Sigma-Aldrich and precleaned before using as substrates.

FTO Pre-Clean Process: FTO substrates were cut into small pieces (area: $1 \mathrm{~cm} \times 3 \mathrm{~cm}$ ) and washed by sonicating in a $(1: 1: 1)$ mixture of acetone (99.9\%), isopropanol $(99.9 \%)$, and water. After rinsing thoroughly with distilled water, the FTO substrates were washed in ethanol (Fluka, 99.8\%) and then dried in air at $300{ }^{\circ} \mathrm{C}$ for $1 \mathrm{~h}$ (heating rate: $\left.8.5^{\circ} \mathrm{C} \mathrm{min}^{-1}\right)$. Then, part of the FTO substrates $(\approx 1 \mathrm{~cm} \times 2 \mathrm{~cm})$ was covered using a polymer tape (Kaptons Foil, VWR International). The uncoated part of the FTO was later employed as electric contact for the working electrodes in the photoelectrochemical cell.

$\mathrm{Fe}_{2} \mathrm{O}_{3}$ Electrodes: Hematite nanowires were prepared according to our previously published procedure. ${ }^{[38]}$ Typically, a $200 \mathrm{~mL}$ Teflon-lined stainless-steel autoclave was filled with $60 \mathrm{~mL}$ aqueous mixture solution of $0.15 \mathrm{~m}$ ferric chloride $\left(\mathrm{FeCl}_{3}, 97 \%\right), 1 \mathrm{~m}$ sodium nitrate $\left(\mathrm{NaNO}_{3}, 99 \%\right)$ and $316 \mu \mathrm{L}$ hydrochloric $(\mathrm{HCl}$, wt $37 \%) .6$ pieces of FTO substrates were put into the autoclave, which was sealed and heated at $95{ }^{\circ} \mathrm{C}$ for $4 \mathrm{~h}$. A homogenous layer of iron oxyhydroxide $(\mathrm{FeOOH})$ nanowires was grown onto the FTO substrate. After that, the $\mathrm{FeOOH}$-coated FTO substrates were washed with deionized water to remove any residual salts, and subsequently pre-sintered in air at $550{ }^{\circ} \mathrm{C}$ (heating rate: $8.5^{\circ} \mathrm{C} \mathrm{min}{ }^{-1}$ ) 
for $2 \mathrm{~h}$ to convert $\mathrm{FeOOH}$ nanowires into hematite nanowires. To further reduce the surface defective sites and improve the crystallinity, the obtained hematite nanowires were post-sintered at $750{ }^{\circ} \mathrm{C}$ in air for additional $30 \mathrm{~min}$ and cooled down to the room temperature in $1 \mathrm{~min}$.

$\mathrm{Fe}_{2} \mathrm{O}_{3} / \mathrm{Fe}_{2} \mathrm{TiO}_{5}$ Electrodes: The obtained hematite samples, after a pre-sintering process $\left(550^{\circ} \mathrm{C}\right.$ for $\left.2 \mathrm{~h}\right)$, were further subjected to an ALD $\mathrm{TiO}_{2}$ process. The ALD $\mathrm{TiO}_{2}$ was performed in a $\mathrm{R} 200$ picosun atomic layer deposition system at $150{ }^{\circ} \mathrm{C}$ with $\mathrm{TiCl}_{4}(99.9 \%)$ and water as the precursors in an 8 mbar $\mathrm{N}_{2}$ flow atmosphere with a growth rate of $0.27 \AA$ per cycle. The pulse time for the $\mathrm{TiCl}_{4}$ and water were $0.1 \mathrm{~s}$ and the purge time was $10 \mathrm{~s}$. The thickness of $\mathrm{TiO}_{2}$ coating onto the $\mathrm{Fe}_{2} \mathrm{O}_{3}$ nanowires can be controlled by changing the ALD deposition cycle. In this case, the optimized $\mathrm{TiO}_{2}$ layer corresponds to 30 cycles according to the previous report. ${ }^{[38]} \mathrm{After}$ that, a post-sintering process at $750{ }^{\circ} \mathrm{C}$ for $30 \mathrm{~min}$ was performed to transform the surface $\mathrm{ALD} \mathrm{TiO}_{2}$ into $\mathrm{Fe}_{2} \mathrm{TiO}_{5} \cdot{ }^{[38,54]}$

$\mathrm{Fe}_{2} \mathrm{O}_{3} / \mathrm{Fe}_{2} \mathrm{TiO}_{5} / \mathrm{CoFe}-\mathrm{PBA}$ Electrodes: The obtained $\mathrm{Fe}_{2} \mathrm{O}_{3} / \mathrm{Fe}_{2} \mathrm{TiO}_{5}$ electrodes were further coated with CoFe-PBA in a chemical bath. ${ }^{25]}$ Chemical bath deposition of CoFe-PBA on the $\mathrm{Fe}_{2} \mathrm{O}_{3} / \mathrm{Fe}_{2} \mathrm{TiO}_{5}$ electrodes were carried out according to the following procedure: First, $\mathrm{Co}\left(\mathrm{NO}_{3}\right)_{26} \mathrm{H}_{2} \mathrm{O}(700 \mathrm{mg})$ and $\mathrm{K}_{3} \mathrm{Fe}(\mathrm{CN})_{6}(350 \mathrm{mg})$ powder were dissolved in $40 \mathrm{~mL}$ of Milli-Q water under vigorous stirring. After that, one piece of $\mathrm{Fe}_{2} \mathrm{O}_{3} / \mathrm{Fe}_{2} \mathrm{TiO}_{5}$ electrodes was immersed in a $5 \mathrm{~mL}$ glass vial with $4 \mathrm{~mL}$ freshly prepared mixture solution containing $\mathrm{Co}\left(\mathrm{NO}_{3}\right)_{2} 6 \mathrm{H}_{2} \mathrm{O}$ $+\mathrm{K}_{3} \mathrm{Fe}(\mathrm{CN})_{6}$. The glass vial was sealed and then heated at $60{ }^{\circ} \mathrm{C}$ for different reaction times in the oven. Finally, the obtained samples were rinsed with Milli-Q water to remove any impurities and were dried in the oven at $60^{\circ} \mathrm{C}$ overnight.

Structural and Morphological Characterization: The grazing incidence X-ray diffraction analyses were conducted on a Bruker D4 X-ray powder diffractometer via using the $\mathrm{Cu}$ Ka radiation $(1.54184 \AA)$ and a 1D Lynkeye detector, which was equipped with a Gobel mirror in the incident beam and equatorial Soller slits in the diffracted beam (51 incidence angle, $2^{\circ}$ per step). The surface morphology of the electrodes was characterized via using a field emission gun scanning electron microscope (FE-SEM, Zeiss Series Auriga microscopy) equipped with an electron dispersive X-ray spectroscopy detector. X-ray photoelectron spectroscopy was performed with a Phoibos 150 analyser (SPECS GmbH, Berlin, Germany)) in an ultrahigh vacuum condition (base pressure $4 \times 10^{-10} \mathrm{mbar}$ ) with a monochromatic aluminium $\mathrm{K}_{\alpha}$ X-ray source $(1486.74 \mathrm{eV})$. The energy resolution was $0.8 \mathrm{eV}$ based on the FWHM measurement of the $\mathrm{Ag} 3 \mathrm{~d}_{5 / 2}$ peak for a sputtered silver foil. Infrared absorption spectroscopy was performed with a ThermoScientific NICOLET iS50 FT-IR spectrometer. Raman Spectrum was conducted at InVia-RENISHAW with incident wavelength: $514 \mathrm{~nm}$. Optical properties of all electrodes were characterized by using a UVvis spectrophotometer (Lambda 950, Perkin Elmer) equipped with an integrating sphere $(150 \mathrm{~mm}$ diameter sphere covered with Spectralon as the reflecting material, Perkin Elmer). Absorbance $(A)$ measurements were obtained from measured reflectance $(R, \%)$ and transmission $(T, \%)$, using a wavelength range from 350 to $800 \mathrm{~nm}$ and a step of $5 \mathrm{~nm}$, respectively. All the samples for HRTEM and ADF-STEM were produced via using a mechanical process. ${ }^{[38]}$ HRTEM and ADF-STEM images were obtained by using a FEI Tecnai F20 field emission gun microscope with a $0.19 \mathrm{~nm}$ point-to-point resolution at $200 \mathrm{kV}$ equipped with an embedded Quantum Gatan image filter for EELS analyses. Atomic resolution AC HAADF STEM and further EELS-STEM analyses were conducted at a FEI TITAN 80-300 STEM operated at $300 \mathrm{kV}$ and a TITAN G3 50-300 PICO operated at $80 \mathrm{kV}{ }^{[59,60]}$ Images were analyzed via using Gatan Digital Micrograph software. The Eje-Z, Rhodius, and JMOL software packages were employed for the atomic supercell modeling with the corresponding crystal phase parameters of each species obtained from the inorganic crystal structure database (ICSD) ${ }^{[61-63]}$ Specifically, to further identify the crystal phases via HRTEM, HAADF STEM, and to probe the spatial distribution of these components in the composite hematite electrodes, we created crystal models based on the single crystal data found in the ICSD. With these crystal models, the diffraction patterns visualized from different zone axes of each species could be simulated. Then, the simulated diffraction pattern was compared with the FFT spectrum obtained on the atomic resolution HRTEM and HAADF STEM experimental images for the identification of the crystal phases in the composite hematite electrodes.

Photo-Electrochemical Measurements: Photocurrent density (j, mA $\mathrm{cm}^{-2}$ ) versus applied potential $(E, V)$ curves were conducted using a three-electrode cell. The working, counter, and reference electrodes were the composite hematite photoanodes $\left(1 \mathrm{~cm}^{2}\right.$ geometric area), a Pt wire, and an $\mathrm{Ag} / \mathrm{AgCl}(3 \mathrm{M} \mathrm{KCl})$ reference electrode (Metrohm, $\mathrm{E}=0.203$ versus $\mathrm{NHE}$ ), respectively. The utilized electrolyte was a $0.1 \mathrm{M} \mathrm{NaNO} \mathrm{N}_{3}+0.1 \mathrm{M} \mathrm{HNO}_{3}$ solution $(\mathrm{pH}=1)$, which was purged with $\mathrm{N}_{2}$ during the experiments. $\mathrm{CV}$ was taken using a computercontrolled potentiostat (VMP3, BioLogic Science Instruments). CV scan was from $0.30 \mathrm{~V}$ versus $\mathrm{Ag} / \mathrm{AgCl}$ to $1.60 \mathrm{~V}$ versus $\mathrm{Ag} / \mathrm{AgCl}$, with a scan rate of $20 \mathrm{mV} \mathrm{s}^{-1}$. The photocurrent density is calculated based on the geometric area. All potentials were corrected at $80 \%$ for the ohmic drop, which was determined using the automatic current interrupt $(\mathrm{Cl})$ method implemented by the potentiostat, ${ }^{[25]}$ and were converted with respect to the RHE: $\mathrm{E}$ ( $V$ versus $\mathrm{RHE}$ ) = E $(\mathrm{V}$ versus $\mathrm{Ag} / \mathrm{AgCl})+0.0592 \times \mathrm{pH}+0.203$. Light illumination calibration was performed using a $150 \mathrm{~W}$ AM $1.5 \mathrm{C}$ solar simulator (Solar Light Co., 16S-300-002 v 4.0) with an incident light intensity set at 1 Sun illumination $\left(100 \mathrm{~mW} \mathrm{~cm}{ }^{-2}\right)$, as measured via using a thermopile (Gentec-EO, XLPF12-3S-H2-DO) coupled with an optical power meter (Gentec-EO UNO). In the PEC characterization, the light came from the front side (hematite-electrolyte interface, front side illumination). All the electrodes were repeated at least three times, and the statistical photocurrent response data at $1.23 \mathrm{~V}$ versus RHE are included in the Supporting Information.

Faradaic Efficiency Measurement: The $\mathrm{O}_{2}$ generated under chronoamperometric conditions ( $1.23 \mathrm{~V}$ versus RHE) during $2 \mathrm{~h}$ and under 1 Sun illumination was measured with the calibrated Fibox detector immersed in the electrolyte in a gastight cell. The oxygen evolution efficiencies were determined from the total amount of charge $Q$ (C) passed through the cell. Assuming that four holes are needed to produce one $\mathrm{O}_{2}$ molecule, the theoretical yield can be calculated as follows:

$n_{\mathrm{O}_{2}}=\frac{Q}{4 F}$

where $F$ is the Faraday constant. The total mole of oxygen produced was quantitatively determined by using a calibrated Fibox detector with a temperature sensor.

Incident Photon to Current Efficiency (IPCE): IPCE was characterized using a xenon light source (Abet $150 \mathrm{~W}$ Xenon Lamp) coupled with a monochromator (Oriel Cornerstone $2601 / 4 \mathrm{~m}$ monochromator). The wavelength was scanned from 350 to $800 \mathrm{~nm}$ (step: $10 \mathrm{~nm}$ step $^{-1}$ ) keeping the voltage fixed at $1.23 \mathrm{~V}$ versus RHE. The IPCE was calculated based on the following equation ${ }^{[38]}$

$\operatorname{IPCE}(\%)=(1240 / \lambda) \times\left(1 / /_{\text {light }}\right) \times 100$

where $I$ is the photocurrent density $\left(\mathrm{mA} \mathrm{cm}{ }^{-2}\right)$ obtained using a potentiostat recording the $I-T$ curve at $1.23 \mathrm{~V}$ versus $\mathrm{RHE}, \lambda$ is the incident light wavelength $(\mathrm{nm})$ from monochromatic, and Jlight $\left(\mathrm{mW} \mathrm{cm}{ }^{-2}\right)$ is the power density of monochromatic light at a specific wavelength. A source meter (Keithley Instruments Inc., model no. 2400) coupled with the standard Silicon Photodiode (Thorlabs, S120VC) was used to measure the power density of monochromatic light.

PEIS Data: PEIS data were obtained with an alternate current perturbation of $5 \mathrm{mV}$ in amplitude and a $100 \mathrm{mHz}$ to $10^{5} \mathrm{~Hz}$ frequency range, both in the dark and under illumination, and under selected direct current potentiostatic conditions ( 0.30 to $1.60 \mathrm{~V}$ vs $\mathrm{Ag} / \mathrm{AgCl})$. Nyquist plots (imaginary vs real components of impedance, $Z_{I m}$ vs $Z_{R e}$ ) were fitted to the corresponding equivalent circuits via using Z-fit (BioLogic Associates). Fitted capacitances and resistances are calculated based on the electrode geometric area $\left(1 \mathrm{~cm}^{2}\right)$. Error bars were derived from the goodness of the EIS data fittings. 


\section{Acknowledgements}

This work was supported by the Spanish Ministerio de Economia y Competitividad (MINECO, Grants CTQ2015-71287-R, CTQ2015-71287-R, and CTQ2015-68770-R) and the coordinated Project ValPEC (ENE201785087-C3), the BIST Ignite Project inWOC2 and the Generalitat de Catalunya (2017 SGR 90, 2017 SGR 327, 2017 SGR 329, 2017 SGR 1246, and 2017 SGR 1406). ICN2 acknowledges the support from the Severo Ochoa Program (MINECO, Grant SEV-2017-0706). ICN2, ICIQ, and IREC are funded by the CERCA Programme/Generalitat de Catalunya. P.Y.T. acknowledges the scholarship support of DAAD short term grant. H.C.D. acknowledges support from the Deutsche Forschungsgemeinschaft (SFB 917). F.S.H. thanks the "LaCaixa"-Severo Ochoa International Programme (Programa internacional de Becas "LaCaixa"- Severo Ochoa) for a Ph.D. fellowship. P.P. and M.H. thank for the support by the Federal Ministry for Economic Affairs and Energy (BMWi) (Fundingregistration number: 03ET6080E). M.L. thanks the COST Action StableNextSol project MP1307, supported by COST (European Cooperation in Science and Technology). H.X. acknowledges the Spanish MINECO through the Severo Ochoa Centers of Excellence Program under Grant SEV-2013-0295 for the postdoctoral contract. The authors acknowledge Dr. Guillaume Sauthier from the ICN2 for the XPS measurements and Dr. Nina $M$. Carretero from IREC for their help in Faradaic efficiency measurement. Part of the the was performed in the framework of Universitat Autònoma de Barcelona Materials Science Ph.D. program.

\section{Conflict of Interest}

The authors declare no conflict of interest.
[11] W. Li, S. W. Sheehan, D. He, Y. M. He, X. H. Yao, R. L. Grimm, G. W. Brudvig, D. W. Wang, Angew. Chem., Int. Ed. 2015, 54, 11428.

[12] J. F. Zhang, R. García-Rodríguez, P. Cameron, S. Eslava, Energy Environ. Sci. 2018, 11, 2972.

[13] S. Chabi, K. M. Papadantonakis, N. S. Lewis, M. S. Freund, Energy Environ. Sci. 2017, 10, 1320.

[14] T. Reier, H. N. Nong, D. Teschner, R. Schlögl, P. Strasser, Adv. Energy Mater. 2017, 7, 1601275.

[15] J. R. McKone, N. S. Lewis, H. B. Gray, Chem. Mater. 2014, 26, 407.

[16] M. Blasco-Ahicart, J. Soriano-López, J. J. Carbó, J. M. Poblet, J. R. Galan-Mascaros, Nat. Chem. 2018, 10, 24.

[17] Q. S. Yin, C. L. Hill, Nat. Chem. 2018, 10, 6.

[18] T. Li, O. Kasian, S. Cherevko, S. Zhang, S. Geiger, C. Scheu, P. Felfer, D. Raabe, B. Gault, K. J. J. Mayrhofer, Nat. Catal. 2018, 1, 300.

[19] R. Frydendal, E. A. Paoli, I. Chorkendorff, J. Rossmeisl, I. E. L. Stephens, Adv. Energy Mater. 2015, 5, 1500991.

[20] S. Kumari, B. P. Ajayi, B. Kumar, J. B. Jasinski, M. K. Sunkara, J. M. Spurgeon, Energy Environ. Sci. 2017, 10, 2432.

[21] I. A. Moreno-Hernandez, C. A. MacFarland, C. G. Read, K. K. Papadantonakis, B. S. Brunschwig, N. S. Lewis, Energy Environ. Sci. 2017, 10, 2103.

[22] L. L. Zhao, Q. Cao, A. L. Wang, J. Z. Duan, W. J. Zhou, Y. H. Sang, H. Liu, Nano Energy 2018, 45, 118.

[23] W. L. Kwong, C. C. Lee, A. Shchukarev, E. Björn, J. Messinger, J. Catal. 2018, 365, 29.

[24] W. L. Kwong, C. C. Lee, A. Shchukarev, J. Messinger, Chem. Commun. 2019, 55, 5017.

[25] L. J. Han, P. Y. Tang, Á. Reyes-Carmona, B. Rodriguez-Garcia, M. Torrens, J. R. Morante, J. Arbiol, J. R. Galan-Mascaros, J. Am. Chem. Soc. 2016, 138, 16037.

[26] B. Rodríguez-García, A. Reyes-Carmona, I. Jiménez-Morales, M. Blasco-Ahicart, S. Cavaliere, M. Dupont, D. Jones, J. Rozière, J. R. Galán-Mascarós, F. Jaouen, Sustainable Energy Fuels 2018, 2, 589.

[27] Y. Y. Zhao, K. R. Yang, Z. C. Wang, X. X. Yan, S. F. Cao, Y. F. Yei, Q. Dong, X. Z. Zhang, J. E. Thorne, L. Jin, K. L. Materna, A. Trimpalish, H. Y. Bai, S. C. Fakrai, X. Y. Zhong, P. Wang, X. Q. Pang, J. H. Guo, M. Flytzani-Stephanopoulos, G. W. Brudvig, V. S. Batistab, D. W. Wang, Proc. Natl. Acad. Sci. USA 2018, 115, 2902.

[28] W. Li, D. He, S. W. Sheehan, Y. M. He, J. E. Thorne, X. H. Yao, G. W. Brudvig, D. W. Wang, Energy Environ. Sci. 2016, 9, 1794.

[29] C. H. Cui, M. Heggen, W. D. Zabka, W. Cui, J. Osterwalder, B. Probst, R. Alberto, Nat. Commun. 2017, 8, 1341.

[30] K. Sivula, F. L. Formal, M. Grätzel, ChemSusChem 2011, 4, 432.

[31] K. G. U. Wijayantha, S. Saremi-Yarahmadi, L. M. Peter, Phys. Chem. Chem. Phys. 2011, 13, 5264.

[32] B. Klahr, S. Gimenez, F. Fabregat-Santiago, T. W. Hamann, J. Bisquert, J. Am. Chem. Soc. 2012, 134, 4294.

[33] A. J. Bard, A. B. Bocarsly, F. R. F. Fan, E. G. Walton, M. S. Wrighton, J. Am. Chem. Soc. 1980, 102, 3671.

[34] Y. B. Kuang, T. Yamada, K. Domen, Joule 2017, 1, 290.

[35] S. Giménez, J. Bisquert, Photoelectrochemical Solar Fuel ProductionFrom Basic Principles To Advanced Devices, [M]. Springer, Berlin 2016.

[36] L. Steier, I. Herraiz-Cardona, S. Gimenez, F. Fabregat-Santiago, J. Bisquert, S. D. Tilley, M. Grätzel, Adv. Funct. Mater. 2014, 24, 7681.

[37] F. S. Hegner, D. Cardenas-Morcoso, S. Gimenez, N. Lopez, J. R. Galan-Mascaros, ChemSusChem 2017, 10, 4552

[38] P. Y. Tang, H. B. Xie, C. Ros, L. J. Han, M. Biset-Peiró, Y. M. He, W. Kramer, A. Perez-Rodriguez, E. Saucedo, J. Galan-Mascaros, T. Andreu, J. R. Morante, J. Arbiol, Energy Environ. Sci. 2017, 10, 2124. 
[39] M. Itoi, T. Jike, D. Nishio-Hamane, S. Udagawa, T. Tsuda, S. Kuwabata, K. Boukheddaden, M. J. Andrus, D. R. Talham, J. Am. Chem. Soc. 2015, 137, 14686.

[40] Y. H. Zhu, J. Ciston, B. Zheng, X. H. Miao, C. Czarnik, Y. C. Pan, R. Sougrat, Z. P. Lai, C. E. Hsiung, K. X. Yao, I. Pinnau, M. Pan, Y. Han, Nat. Mater. 2017, 16, 532

[41] D. L. Zhang, Y. H. Zhu, L. M. Liu, X. R. Ying, C. E. Hsiung, R. Sougrat, K. Li, Y. Han, Science 2018, 359, 675.

[42] M. Martin-Sabi, J. Soriano-López, R. S. Winter, J. J. Chen, L. Vilà-Nadal, D. L. Long, J. R. Galán-Mascarós, L. Cronin, Nat Catal. 2018, 1, 208.

[43] S. Pintado, S. Goberna-Ferron, E. C. Escudero-Adan, J. R. Galan-Mascaros, J. Am. Chem. Soc. 2013, 135, 13270.

[44] B. Klahr, T. Hamann, J. Phys. Chem. C 2014, 118, 10393.

[45] O. Zandi, T. W. Hamann, J. Phys. Chem. Lett. 2014, 5, 1522.

[46] J. Suntivich, K. J. May, H. A. Gasteiger, J. B. Goodenough, S. H. Yang, Science 2011, 334, 1383.

[47] J. Li, R. Peat, L. Peter, J. Electroanal. Chem. Interfacial Electrochem. $1984,165,41$

[48] O. Zandi, T. W. Hamann, Nat. Chem. 2016, 8, 778.

[49] B. Iandolo, A. Hellman, Angew. Chem. 2014, 126, 13622.

[50] M. Sachsenhauser, I. D. Sharp, M. Stutzmann, J. A. Garrido, J. Phys. Chem. C 2016, 120, 6524.

[51] M. R. Nellist, F. A. L. Laskowski, J. J. Qiu, H. Hajibabaei, K. Sivula, T. W. Hamann, S. W. Boettcher, Nat. Energy 2018, 3, 46.
[52] N. Yatom, O. Neufeld, M. C. Toroker, J. Phys. Chem. C 2015, 119, 24789.

[53] N. Yatom, Y. Elbaz, S. Navona, M. C. Toroker, Phys. Chem. Chem. Phys. 2017, 19, 17278.

[54] D. M. Satoca, M. Bartsch, C. Fabrega, A. Genç, S. Reinhard, T. Andreu, J. Arbiol, M. Niederberger, J. R. Morante, Energy Environ. Sci. 2015, 8, 3242.

[55] T. L. Villarreal, R. Gómez, M. Neumann-Spallart, N. Alonso-Vante, P. Salvador, J. Phys. Chem. B 2004, 108, 15172.

[56] B. Klahr, S. Gimenez, F. Fabregat-Santiago, J. Bisquert, T. W. Hamann, Energy Environ. Sci. 2012, 5, 7626.

[57] K. G. Upul Wijayantha, S. Saremi-Yarahmadi, L. M. Peter, Phys. Chem. Chem. Phys. 2011, 13, 5264.

[58] E. A. Ponomarev, L. M. Peter, J. Electroanal. Chem. 1995, 397, 45.

[59] M. Heggen, M. Luysberg, K. Tillmann, J. Large-Scale Res. Facil. 2016, 2, 42.

[60] J. Barthel, L. Houben, K. Tillmann, J. Large-Scale Res. Facil. 2015, 1, 34.

[61] M. D. L. Mata, R. Leturcq, S. R. Plissard, C. Rolland, C. Magen, J. Arbiol, P. Caroff, Nano Lett. 2016, 16, 825.

[62] S. Bernal, F. J. Botana, J. J. Calvino, C. Lopez-Cartes, J. A. Perez-Omil, Ultramicroscopy 1998, 72, 135.

[63] R. R. Zamani, M. Ibanez, M. Luysberg, N. Garcia-Castello, L. Houben, J. D. Prades, V. Grillo, R. E. Dunin-Borkowski, J. R. Morante, A. Cabot, J. Arbiol, ACS Nano 2014, 8, 2290. 